\title{
PALEOCORRENTES, PALEOGEOGRAFIA E SEQÜÊNCIAS DEPOSICIONAIS DA FORMAÇÃO TATUÍ, CENTRO-LESTE DO ESTADO DE SÃO PAULO
}

\author{
MARIO LUIS ASSINE ${ }^{1}$, ANGÉLICA ÁLIDA ZACHARIAS ${ }^{2}$ \\ \& JOSÉ ALEXANDRE J. PERINOTTO ${ }^{1,3}$
}

\begin{abstract}
PALEOCURRENTS, PALEOGEOGRAPHY AND DEPOSITIONAL SEQUENCES IN THE TATUI FORMATION, BRAZIL Coarse-grained sandstones and conglomerates rich in silex clasts are conspicuous facies of the Tatuí Formation in the eastcentral São Paulo State, Brazil. They represent a progradation of coastal alluvial fan systems (Ibicatu) on a marine shelf. Paleocurrents indicate depositional dip towards the south, paleoshoreline with an approximate east-west direction and sediment provenance from the North. The upper part of the Tatuí Formation, interpreted as a highstand system tract, was covered by transgressive shales of the Taquaral Member (Irati Formation). During the transgressive phase, sediments of the Tatuí Formation were partially reworked by marine erosive processes, with development of wave ravinement surfaces and deposition of thin levels of conglomerates rich in silex grains, pebbles and bioclasts (scales, teeth and bones of fish and coprolites). The conglomerates are transgressive lags at the base of the Taquaral transgressive system tract.
\end{abstract}

Keywords: paleocurrents, paleogeography, depositional sequences, Tatuí Formation, Paraná basin, Permian

Resumo A presença de níveis de arenitos grossos e conglomerados, ricos em clastos de sílex, é característica marcante da parte superior da Formação Tatuí no centro-leste do Estado de São Paulo. Pertencem a um trato de sistemas de mar alto caracterizado pela progradação de sistemas de leques aluviais costeiros (Ibicatu) sobre uma plataforma marinha dominada por marés. Paleocorrentes indicam mergulho deposicional para sul, paleolinha de costa na direção aproximada leste-oeste e área-fonte a norte da área estudada. O trato deposicional da parte superior da Formação Tatuí foi recoberto pelos folhelhos transgressivos do Membro Taquaral (Formação Irati). Durante a transgressão houve retrabalhamento de parte dos sedimentos da Formação Tatuí por agentes marinhos costeiros, gerando superfícies de ravinamento por onda, sobre as quais ocorrem níveis delgados de conglomerados ricos em grânulos e seixos de sílex e bioclastos (escamas, dentes e espinhos de nadadeiras de peixes e coprólitos). Estes níveis de conglomerados constituem a base do trato de sistemas transgressivo Taquaral, tendo sido interpretados como depósitos residuais transgressivos.

Palavras-chave: paleocorrentes, paleogeografia, sequiências deposicionais, Formação Tatuí, Bacia do Paraná, Permiano

INTRODUÇÃO A Formação Tatuí é de idade eopermiana e cronocorrelata às formações Rio Bonito e Palermo reconhecidas nos estados do sul do Brasil, compondo em conjunto o Grupo Guatá segundo concepção de Gordon Jr. (1947). A Formação Tatuí apresenta-se bem desenvolvida na faixa de afloramentos do centro-leste do Estado de São Paulo, área onde foram desenvolvidos as principais pesquisas sobre a unidade e que é objeto de estudo neste trabalho (Fig. 1).

Com base no levantamento de várias seções estratigráficas na área, Soares (1972) reconheceu quatro descontinuidades na Formação Tatuí (Fig. 2), estabelecendo o arcabouço estratigráfico da unidade. A desconformidade basal, que denominou L1, foi pelo referido autor considerada a superfície erosiva mais expressiva, separando o ciclo glacial (Grupo Itararé) do pós-glacial (Formação Tatuí). A descontinuidade L2 foi a base para a subdivisão da Formação Tatuí em dois membros: 1) um membro inferior constituído predominantemente por lamitos de coloração marrom- arroxeada; 2) um membro superior constituído por lamitos cinza-esverdeados, arenitos e calcários, com uma descontinuidade interna L3. Embora não tenha feito considerações sobre a paleogeografia, a seção estratigráfica apresentada por Soares (1972) é sugestiva de que a área-fonte situava-se a norte à epoca da deposição da Formação Tatuí. A descontinuidade L4, que separa a Formação Tatuí da Formação Irati (Membro Taquaral), já havia sido reconhecida anteriormente por Barbosa \& Almeida (1949).

Trabalhos posteriores apresentaram interpretações da paleogeografia à época da deposição. Fulfaro et al. (1984) interpretaram um complexo deltaico mais antigo com fluxo de sudeste para noroeste, sucedido na parte superior da unidade por sistemas flúvio-deltaicos e de leques costeiros, que teriam avançado para sul sobre um golfo dominado por fácies marinhas de águas rasas, conectado com o oceano a sudoeste. Stevaux et al. (1986) mantiveram a correlação apresentada por Fulfaro et al. (1984), apresentando um modelo de trato deposicional para a porção superior da Formação Tatuí, composto por leques deltaicos provenientes do Alto de Ibicatu a norte, passando lateralmente para depósitos litorâneos (barras de maré) até depósitos de plataforma com sedimentação pelito-carbonática a sul. Riccomini et al. (1997),

1 - Unesp - Campus de Rio Claro - Departamento de Geologia Aplicada - Avenida 24-A, 1515 13506-900 Rio Claro-SP e-mail: assine@rc.unesp.br

2 - Unesp - Campus de Rio Claro - Curso de Pós-Graduação em Geociências

3 - UnG - Universidade de Guarulhos - CEPPE - Praça Terezqa Cristina, 58, 07023-070 - Guarulhos - SP 


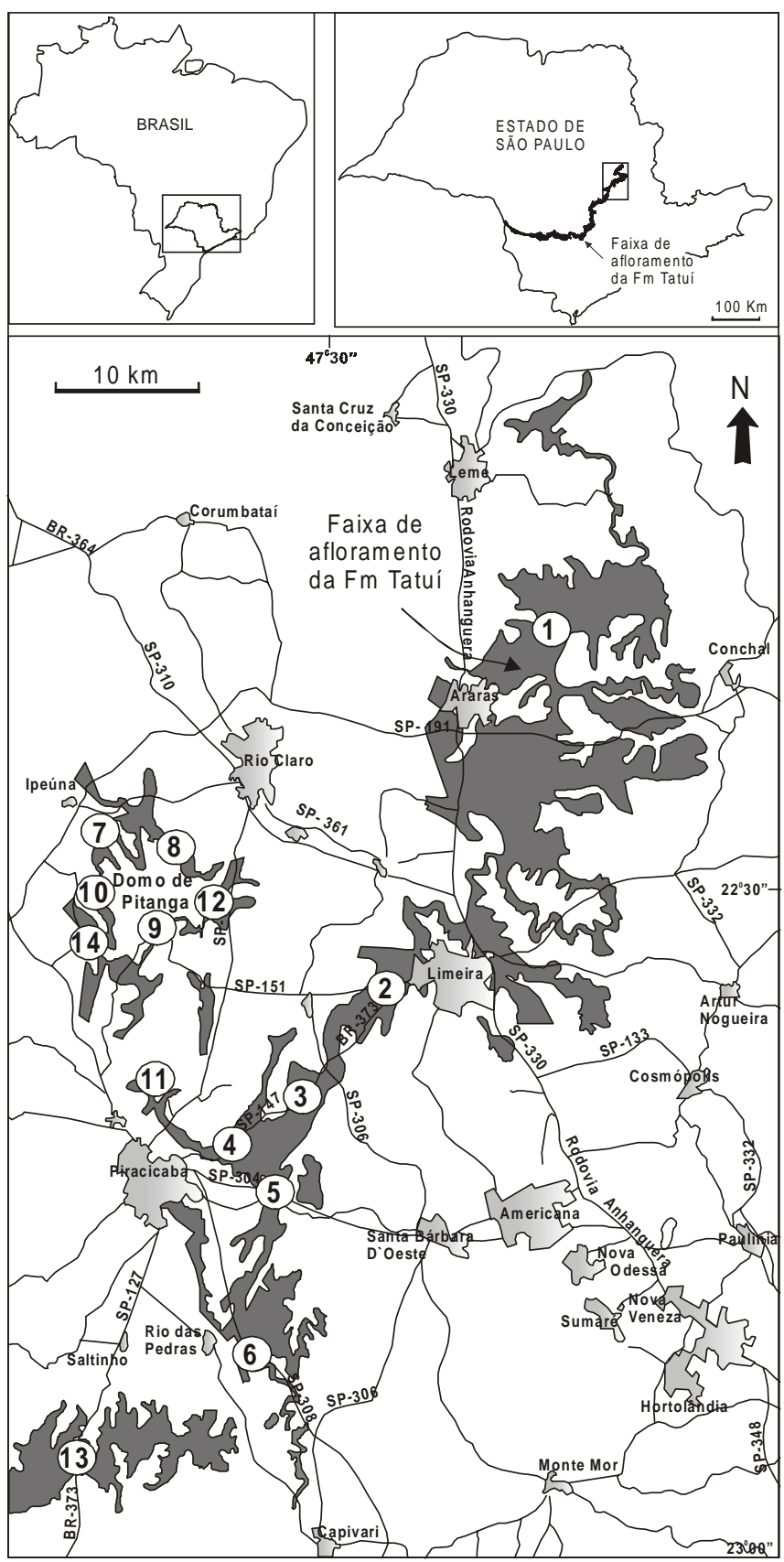

Figura 1 - Mapa de localização da área estudada. Coordenadas UTM dos pontos indicados: 1) 266.780 e 7.537.257; 2) 246.690 e 7.501 .826 ; 3) 244.211 e 7.496.320; 4) 237.982 e 7.493.474; 5) 238.847 e 7.484.030; 6) 235.338 e 7.475.397; 7) 224.250 e $7.515 .750 ; 8) 231.689$ e $7.509 .090 ; 9) 228.650$ e 7.505 .550 ; 10) 223.495 e 7.505 .121 ; 11) 225.050 e 7.494.750; 12) 231.800 e 7.508 .950 ; 13) 221.228 e 7.460 .900 ; 14) 221.449 e 7.505.526.

com base na distribuição lateral e vertical das distintas fácies no topo da Formação Tatuí, aventaram modelo com rios entrelaçados fluindo de noroeste para sudeste, formando progradações deltaicas sobre sedimentos marinhos.

Buscando rediscutir a paleogeografia à luz da análise de paleocorrentes, a faixa de afloramentos da Formação Tatuí no centro-leste do Estado de São Paulo foi revisitada, sendo descritas as fácies sedimentares que permitissem a obtenção de medidas de paleocorrentes. Os perfis estratigráficos verticais levantados permitiram também reinterpretar a arquitetura estratigráfica da unidade sob a ótica da Estratigrafia de Seqüências. Resultados preliminares foram apresentados em Assine et al. (1999).

FÁCIESSEDIMENTARESE PALEOCORRENTES Tendoem vista que no membro inferior ocorrem muito restritamente fácies com elementos passíveis de medição de paleocorrentes, já que a unidade se caracteriza como uma seção monótona de lamitos, o trabalho desenvolvido foi concentrado sobretudo no estudo das fácies do membro superior.

As medidas de paleocorrentes concentraram-se em cinco fácies principais, compondo um conjunto de dados consistentes para a reconstituição dos paleofluxos sedimentares e para a interpretação paleogeográfica. Os principais pontos descritos, cujos dados estão discutidos no texto, têm sua posição geográfica indicada na figura 1.

Arenitos finos com estratificação cruzada hummocky Esta fácies ocorre intercalada em lamitos e é constituída por arenitos brancos com tonalidades esverdeadas, finos a muito finos, micáceos (muscovita e biotita), com estratificação cruzada hummocky. Os arenitos são interpretados como depósitos de barras marinhas formadas pela ação de ondas, abaixo do nivel de base das ondas de tempo bom e acima do nível de base das ondas de tempestade. Afloramento representativo é o do $\mathrm{km} 62$ da rodovia SP-127, situado entre Tietê e Piracicaba (Ponto 13; Fig. 3-A).

Os sentidos de transporte deduzidos dos estratos cruzados indicam que o fluxo não foi de natureza essencialmente oscilatória. Embora os dados mostrem grande dispersão, há uma tendência de fluxo com moda para NNE em oposição a uma outra moda para SSW (Fig. 3-B). O eixo de simetria das modas $\left(\sim 110^{\circ}\right)$ é compatível com os eixos das ondulações de onda medidos, que estão orientados segundo as direções E-W e ESE-WNW.

Conglomerados Conglomerados clasto-sustentados (Fig. 4-A), nos quais predominam seixos de quartzo e de sílex, que localmente se apresentam imbricados. Frequientemente exibem estratificação cruzada planar e são portadores de fragmentos decimétricos a métricos de troncos silicificados. Os conglomerados são interpretados como depósitos de origem aluvial, depositados por fluxos canalizados, onde migração de formas de leito 2D e 3D foram as responsáveis pela origem das camadas com estratificações cruzadas planares e acanaladas.

Ocorrem associados a arenitos finos a médios na parte superior da Formação Tatuí, pouco abaixo do contato com o Membro Taquaral. Os conglomerados são mais expressivos no segmento mais setentrional da faixa de afloramentos, atingindo espessuras da ordem de nove metros a norte da cidade de Araras (Ponto 1; Fig. 5-A), onde medidas nas camadas frontais dos estratos cruzados revelaram paleocorrentes para SE. Localmente podem apresentar aspecto maciço e grande concentração de clastos angulosos de sílex , como no córrego Paraíso no distrito de Paraisolândia, Município de Charqueada (Ponto 14; Fig. 4-B e 5-B).

Arenitos seixosos com estratificação cruzada planar Arenitos grossos a muito grossos, com seixos de quartzo e sílex, formando "sets" de até $2,5 \mathrm{~m}$ de espessura, que apresentam estratificação 
Mario Luis Assine et al.

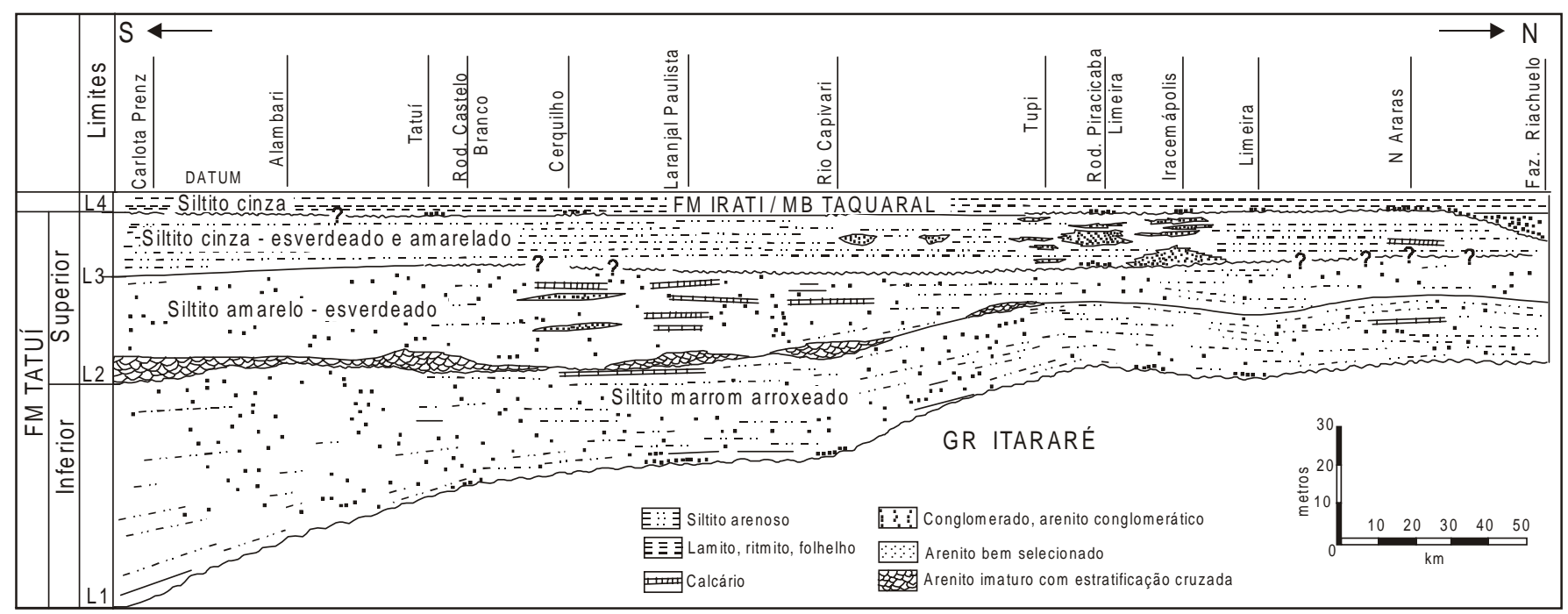

Figura 2 - Seção estratigráfica com datum na base do Membro Assistência da Formação Irati (Soares 1972).


Figura 3 - Arenitos finos a muito finos na base do membro superior (Ponto 13): A) estratificação cruzada hummocky; B) roseta de paleocorrentes.
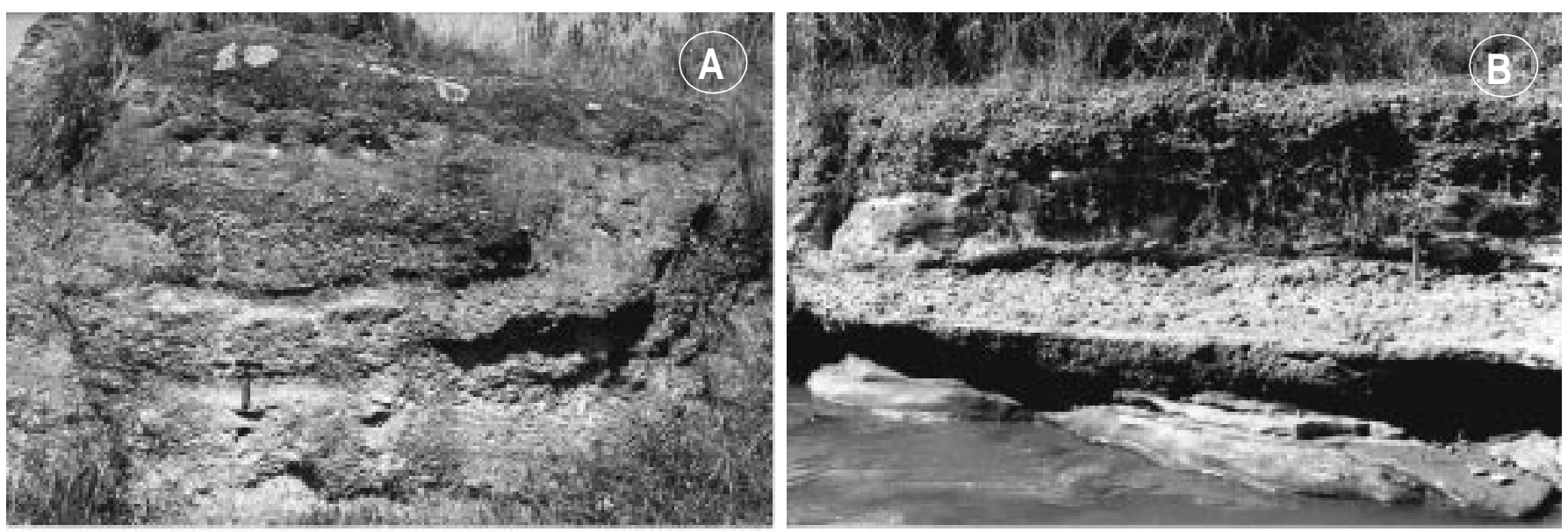

Figura 4 - Conglomerados: A) com estratificação cruzada acanalada, ponto 1, a norte-nordeste da cidade de Araras; B) interestratificados com arenitos, ponto 14, no distrito de Paraisolândia, Município de Charqueada. 




Figura 5 - Perfis estratigráficos verticais: A) Ponto 1; B) Ponto 14; C) Ponto 2; D) Ponto 5.

cruzada planar. As camadas podem possuir forma lenticular a sigmóide, como no córrego do Veado na rodovia SP-151 entre Limeira e Iracemápolis (Ponto 2, Fig. 5-C). As paleocorrentes medidas são consistentes com paleofluxo para sul (azimute $188^{\circ}$ ), a partir da área de Ibicatu.

Para sul o tamanho de grão diminui, predominando arenitos grossos a médios com estratificação tabular planar. No km 122,1 da rodovia SP-147, entre Piracicaba e Limeira (Ponto 3), os arenitos encontram-se deformados por falhas normais sindeposicionais de direção NW-SE e caimento SW, descritas por Morales et al. (1997). $\mathrm{O}$ mergulho das falhas normais coincide com as direções das paleocorrentes medidas nos estratos frontais dos estratos cruzados, cujo vetor médio indica transporte para SW (azimute $223^{\circ}$ ).

Arenitos com gradação normal Fácies de arenitos finos a grossos com gradação normal, formando camadas centimétricas a decimétricas de base plana e topo convexo que ocorrem intercaladas em lamitos e siltitos cinza-esverdeados. Os arenitos são geralmente maciços, embora várias camadas apresentem laminação cruzada cavalgante ou estratificaçao cruzada planar (Fig. 6). Medidas de paleocorrentes feitas em afloramento na SP-308, entre Limeira a Piracicaba, no anel viário para a rodovia do Açúcar (Ponto 4), mostram padrão unidirecional com fluxo sedimentar predominante para sul (azimute $\left.166^{\circ}\right)$.

Arenitos com estratificação cruzada sigmóide Fácies constituída por arenitos grossos a médios, com seixos e grânulos de sílex dispersos, dispostos em camadas com forma sigmóide e espessu- ra de alguns decímetros até dois metros. As camadas apresentamse sob a forma de barras amalgamadas e justapostas lateralmente, formando níveis contínuos de mais de $100 \mathrm{~m}$ de extensão. Cada barra arenosa é internamente caracterizada por estratificação cruzada sigmóide e gradação para lamitos na terminação basal das sigmóides. As barras podem apresentar icnofósseis no seu dorso e recobrimentos (drapes) de argila entre duas barras superpostas, indicando redução na energia de transporte e decantação de finos. Esta fácies ocorre sobretudo na parte sul da área estudada (Fig. 7). Paleocorrentes medidas no km 152,5 da SP-308, rodovia do Açúcar, entre Piracicaba e Rio das Pedras (Ponto 6), indicam transporte sedimentar para sul-sudoeste (azimute médio $200^{\circ}$ ).

PALEOCORRENTES E PALEOGEOGRAFIA As diferentes fácies sedimentares da parte superior da Formação Tatuí mostram um padrão bem definido de paleofluxo sedimentar geral para sul (Fig. 8). Os dados levantados corroboram as interpretações de Fulfaro et al. (1984) e de Stevaux et al. (1986), que conceberam para a parte superior da Formação Tatuí um trato deposicional em que depósitos aluviais passam, em direção a sul, para depósitos de mar raso com barras de maré e depósitos de plataforma com sedimentação pelito-carbonática.

Os conglomerados e arenitos conglomeráticos com estratificação cruzada, portadores de madeira silicificada, que ocorrem na parte norte da faixa de afloramentos constituem as fácies mais proximais do trato deposicional. Tais fácies são interpretadas como depósitos aluviais de leques costeiros. As paleocorrentes, deduzidas a partir dos estratos cruzados, indicam paleofluxo para 


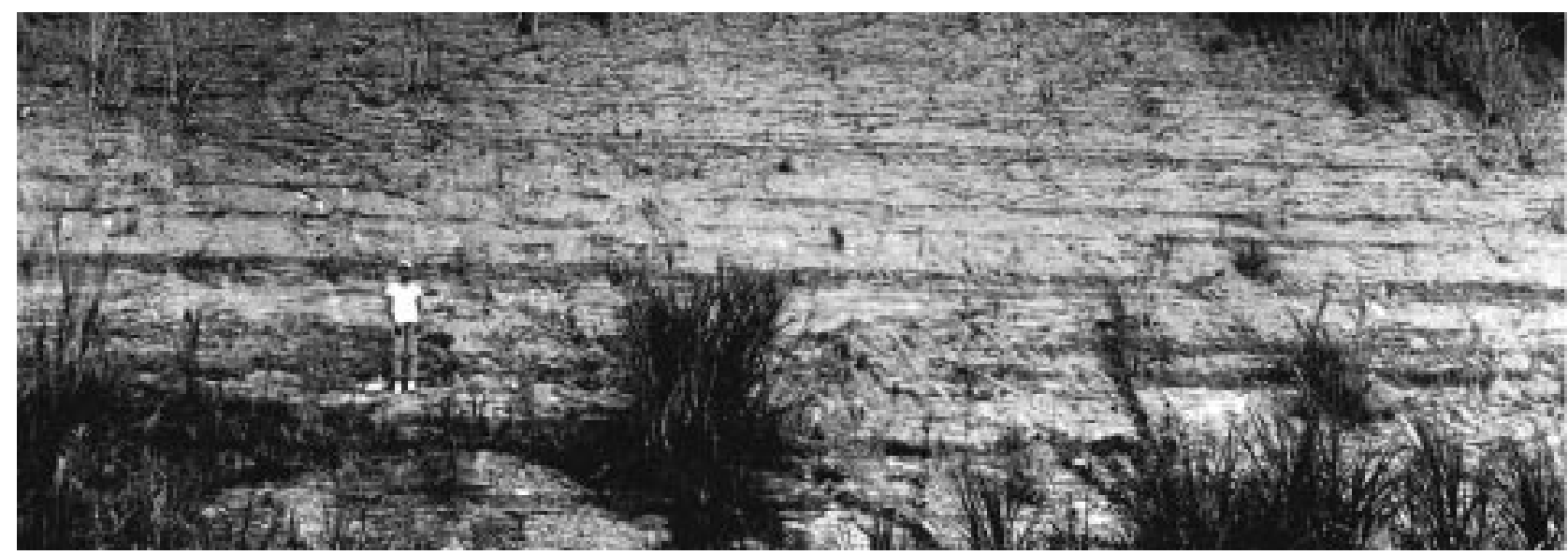

Figura 6 - Corpos de arenitos com gradação normal intercalados em pelitos (Ponto 4).

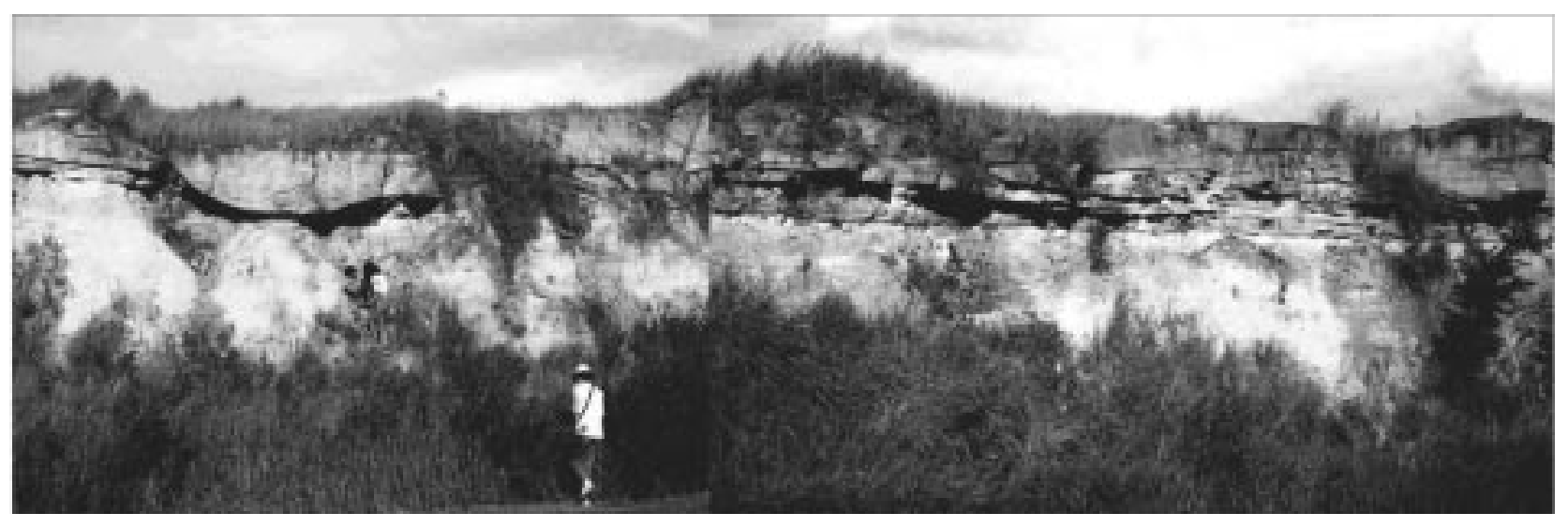

Figura 7 - Corpos de arenitos com forma e estratificação cruzada sigmóide. Lâminas de siltito ocorrem intercaladas na parte basal dos estratos cruzados, que gradam lateralmente para lamitos cinza- esverdeados fluxo abaixo (Ponto 6)

SE, compatível com transporte para sul deduzido a partir de medidas de imbricação dos seixos, cujo eixos "a" mostram orientação E-W.

Os depósitos aluviais são lateralmente contíguos a arenitos seixosos com estratificação cruzada e a arenitos tabulares com gradação normal. Tais fácies, interpretadas como depósitos de ambientes costeiros, ocorrem intercaladas numa sucessão de lamitos e arenitos finos com acamamentos ondulado (wavy bedding), lenticular (linsen) e flaser, o que sugere a influência de correntes de maré. A interpretação de ambiente costeiro é corroborada pela presença de foraminíferos de ambiente marinho nos lamitos, relatados em Fulfaro et al. (1984).

Assim como nos depósitos aluviais, as paleocorrentes nos progradacionais costeiros são coerentes com área-fonte situada a norte, o que explica satisfatoriamente a orientação dos troncos de madeira silicificada em arenitos finos a médios, interpretados como depósitos de canais distributários e descritos no perfil levantado no km 151 da rodovia SP-304, proximidades de Tupi, entre Piracicaba e Santa Bárbara D’Oeste (Ponto 5; Figs. 5-D e 9),

Neste contexto, o caimento para sudoeste das falhas sindeposicionais descritas por Morales et al. (1997) seriam produto de deslizamento rotacional lístrico em direção ao centro da ba- cia em conseqüência de progradação dos leques costeiros sobre lamitos marinhos.

As paleocorrentes medidas nas fácies aluviais e costeiras, apresentadas acima, permitem concluir que o paleomergulho deposicional da bacia era para sul, do que se deduz que a paleolinha de costa tinha direção aproximada E-W. Desta forma, por coincidirem com o sentido de proveniência dos sistemas costeiros, as paleocorrentes também para sul nos arenitos sigmóides (Fig. 8) evidenciam predomínio de correntes de maré vazante.

Algumas estruturas tendem a ter orientação paralela à linha de costa, como eixos de ondulações de onda. Medidas de eixos feitas nos arenitos com estratificação cruzada hummocky presentes na base do membro superior apresentaram orientações E-W e ESEWNW compatíveis com a paleolinha de costa deduzida. Modas para NNE e SSW dos fluxos em arenitos com estratificação cruzada hummocky corroboraram dados de orientação dos eixos de onda, delineando eixo de simetria na direção aproximada ESSEWNW na roseta de paleocorrentes da figura 3-B. Estes dados, entretanto, não são estatisticamente suficientes para assumir estas inferências, havendo necessidade de trabalhos futuros para verificar se o padrão observado nestes arenitos é consistente.

Por outro lado, os indicadores de paleocorrentes medidos não 




Figura 8 - Mapa de paleocorrentes no membro superior da Formação Tatuí. Paleocorrentes para o rumo geral sul indicam áreafonte a norte. A interpretação de linha de costa na direção aproximada leste-oeste é corroborada por medidadas do eixo de ondulações de onda e pelo eixo de simetria apresentado no diagrama em rosa dos arenitos com estratificação cruzada hymmocky.

permitiram verificar a existência de sistemas deltaicos com progradação para noroeste, interpretados por Fulfaro et al. (1984) no que consideraram ser a parte média da Formação Tatuí.

SEQÜÊNCIAS DEPOSICIONAIS Segundo Soares (1972), a descontinuidade L2 é uma superfície de erosão subaérea, pois é recoberta por arenitos com estratificação cruzada acanalada, interpretados como depósitos fluviais. Arenitos finos portadores de troncos silicificados, depositados em ambientes sedimentares com influência terrestre, foram constatados nas proximidades de Tupi (Ponto 5), comprovando a descontinuidade preconizada. Mas, num dos afloramentos mais representativos destes arenitos (ponto 13, perfil Rio Capivari da Fig. 1) verificou-se que as estratificações cruzadas são do tipo hummocky, sendo por isso interpretados como fácies de barras subaquosas (marinhas) retrabalhadas por ondas.

$\mathrm{O}$ fato de que os arenitos da base do membro superior possam ser em parte marinhos não invalida, entretanto, a interpretação de uma descontinuidade entre os membros superior e inferior. $\mathrm{O}$ aparecimento abrupto de fácies regressivas (arenitos retrabalhados por ondas) sobre lamitos marrom chocolate marinhos, indica abai- xamento do nível de base e ingressão de sedimentos de granulação mais grossa na bacia. Assim, embora não tenha a amplitude considerada por Soares (1972), a desconformidade L2 pode ser interpretada como limite de duas seqüências deposicionais. Desconformidade a norte com conformidade correlata a sul pode ser inferida a partir da seção estratigráfica da figura 2, o que é coerente com paleolinha de costa na direção aproximada E-W, deduzida a partir das paleocorrentes.

Os arenitos da base do membro superior são recobertos por lamitos marinhos cinza-esverdeados com intercalações de calcários, representando um conjunto transgressivo. Nesse contexto, a superfície L3 de Soares (1972), sobre a qual ocorrem níveis delgados de conglomerados, provavelmente é uma superfície transgressiva, conforme interpretação de Câmara Filho (1997).

Os sistemas de leques aluviais costeiros (cunha clástica Ibicatu) progradantes sobre sistemas marinhos dominados por ondas e marés, conforme modelo de trato deposicional proposto por Stevaux et al. (1986) para a parte superior da Formação Tatuí, são interpretados no conjunto como trato de sistemas de mar alto. $\mathrm{O}$ arranjo lateral de fácies neste trato é ilustrado pela seção estratigráfica esquematizada na figura 10.

O contato entre as formações Tatuí e Irati (Membro Taquaral) é dado pela descontinuidade L4 de Soares (1972), que é marcada, em muitos locais, por delgados níveis de conglomerados maciços clasto-sustentados, ricos em grânulos e seixos de sílex e de bioclastos (escamas, dentes e espinhos de nadadeiras de peixes e coprólitos), com espessura de 1 a $20 \mathrm{~cm}$, descritos anteriormente por vários autores (Mezzalira 1957, Barbosa \& Gomes 1958, Ragonha 1978).

As camadas de conglomerados são descontínuas lateralmente, mas têm expressão regional. Foram observadas em vários locais, merecendo destaque as ocorrências no Domo de Pitanga, que se estende pelos municípios de Piracicaba, Rio Claro e Charqueada (Pontos 7, 8, 9, 10, 12 e 14). Embora seja mais freqüente no contato entre a Formação Tatuí e o Membro Taquaral (Formação Irati), podem ocorrer também decímetros acima dele, como se depreende dos perfis apresentados por (Riccomini et al. 1997).

A camada de conglomerados ocorre também no contato da Formação Tatuí com o Membro Taquaral a nordeste da cidade de Araras, acima dos arenitos e conglomerados da parte superior da Formação Tatuí (Ponto 1; Fig. 5-A). Desta forma, a descontinuidade L4 está situada sobre a cunha clástica Ibicatu, ao contrário da concepção inicial de Soares (1972) ilustrada na figura 2.

Pela sua posição estratigráfica e características faciológicas, as delgadas camadas de conglomerados, ricas em seixos e grânulos de sílex e de bioclastos, são interpretadas como depósitos residuais (lags) transgressivos (Fig. 11), formados durante elevação relativa do nível do mar. Estes níveis já haviam sido anteriormente considerados pavimentos transgressivos por Castro et al. (1993).

Os sedimentos depositados por sistemas de leques costeiros são retrabalhados por ondas com a transgressão, sofrendo processo de joeiramento (winnowing). Neste processo, os sedimentos mais finos são removidos pelas correntes e a fração grossa fica concentrada como depósitos residuais (lags) sobre superfícies de ravinamento por onda. No processo, os eixos "a" dos seixos tendem a ficar orientados paralelamente à linha de costa. Medidas realizadas em dois pontos mostram eixos "a" orientados entre ENE e ESE (Fig.8), corroborando as interpretações feitas para o membro superior da Formação Tatuí, onde foi interpretada paleolinha de costa na direção aproximada E-W.

A espessura dos depósitos residuais diminui para sul. Em La- 


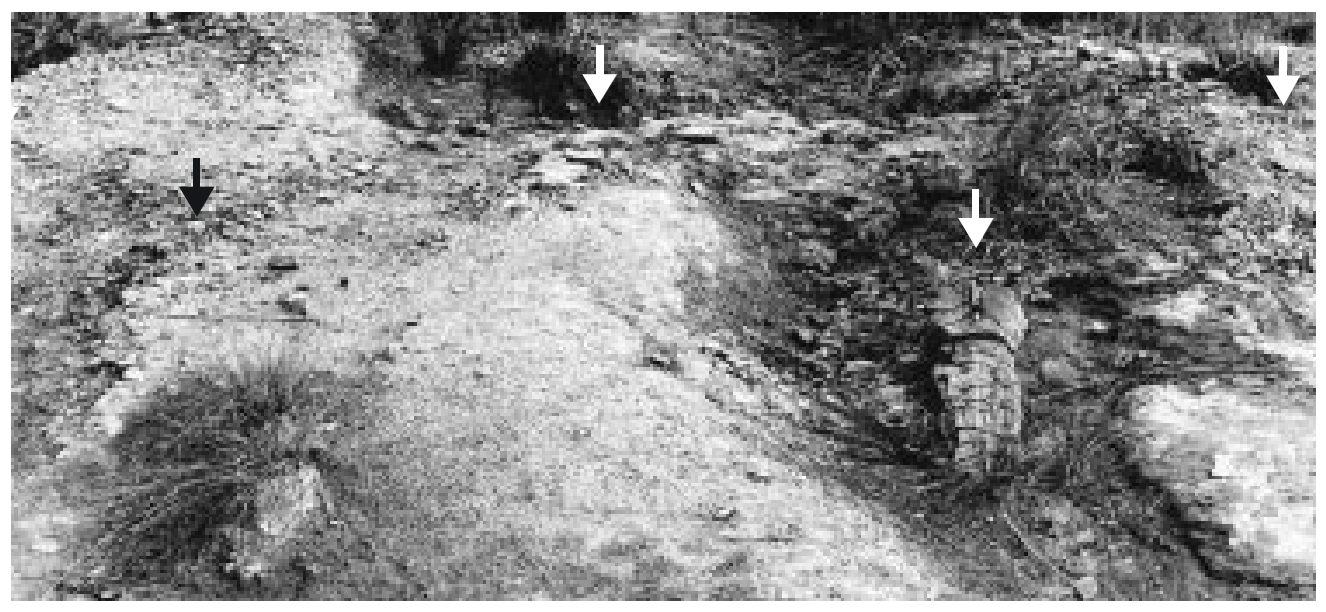

Figura 9 - Arenitos finos a médios, portadores de troncos de madeira silicificada alinhados na direção N-S (Ponto 5).

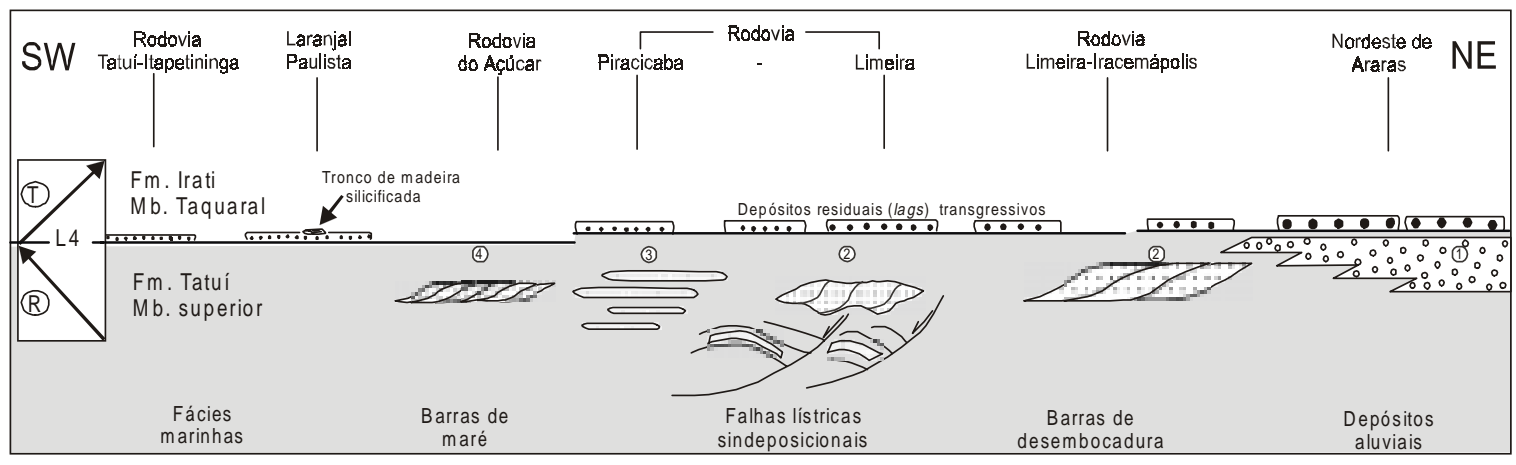

Figura 10 - Seção estratigráfica esquemática $(R=$ regressão $; T=$ transgressão $;$ LA = descontinuidade entre as formações Tatuí e Irati; 1 = conglomerados aluviais; 2 = corpos sigmóides costeiros; 3 = arenitos tabulares com gradação normal; $4=$ sigmóides de maré).
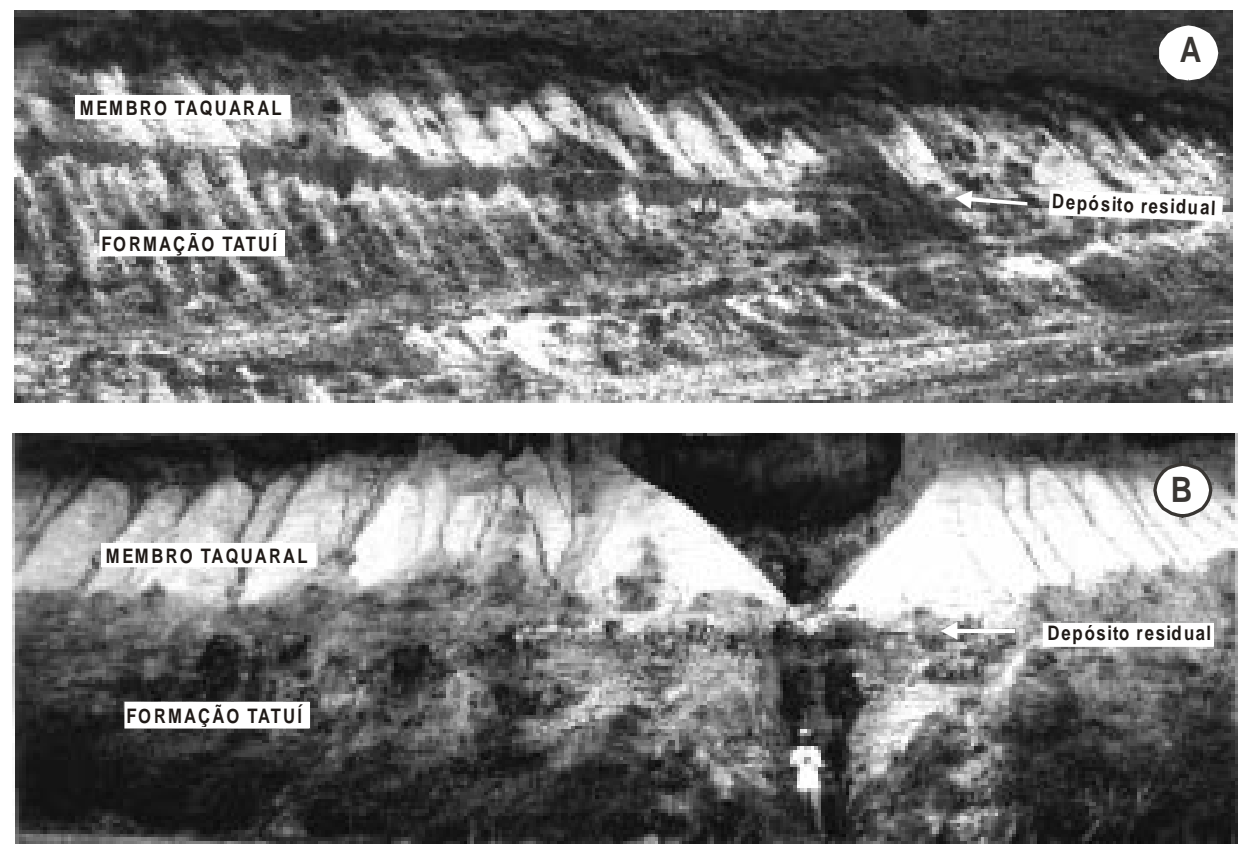

Figura 11 - Depósitos residuais no contato entre a Formação Tatuí e o Membro Taquaral da Formação Irati (ponto 5). 
ranjal Paulista, um nível delgado de grânulos e restos fósseis ocorre no contato entre as duas unidades, onde foi encontrado um fragmento cilíndrico de madeira silicificada com cerca de seis centímetros de comprimento. Mais a sul, entre Tatuí e Itapetininga, constituem lâminas com concentração de ictiofósseis descritas por Ragonha (1978).

A elevação do nível do mar causou redução no aporte sedimentar e o trato deposicional da parte superior da Formação Tatuí foi recoberto em onlap marinho pelas fácies transgressivas do Membro Taquaral da Formação Irati. Durante a transgressão, os depósitos costeiros/marinhos foram retrabalhados pelos agentes marinhos gerando superfícies de ravinamento por onda.

O contato entre as formações Tatuí e Irati representa, portanto, limite natural entre duas sequiências deposicionais, definido pela superposição de um trato de sistemas transgressivo (Taquaral) sobre um de mar alto (Tatuí), sem a interveniência de um trato de sistemas de mar baixo. O limite entre as duas seqüências é dado pelas superfícies de ravinamento, sobre as quais ocorrem depósitos residuais (lags) transgressivos de conglomerados clasto-sustentados ou, simplesmente, pavimentos de clastos.

CONSIDERAÇÕES FINAIS Embora a correlação da Formação Tatuí com as formações Palermo e Rio Bonito seja aceita, dúvidas persistem quanto à correlação fina entre as seções sedimentares das referidas unidades. Castro \& Câmara Filho (1995) considera- ram a parte superior da Formação Tatuí correlata aos membros Paraguaçu e Siderópolis, este último representado pelo que chamaram “cunha clástica Ibicatu-Rio das Pedras". Perinotto (1992), por outro lado, já havia analisado a mesma seção, tendo-a considerado no contexto da Formação Palermo. Novos dados são ainda necessários para o refinamento das correlações lito- e cronoestratigráficas.

Por fim, é importante enfatizar que os níveis de conglomerados que ocorrem como depósitos residuais transgressivos no contato entre as formações Tatuí e Irati (L4 de Soares, 1972), são estratigraficamente distintos dos conglomerados e arenitos grossos com clastos de sílex que ocorrem inseridos na parte superior da Formação Tatuí e que informalmente são referidos como "fácies Ibicatu“. A fim de evitar impropriedades e falhas na comunicação geológica, propõe-se reservar o nome Ibicatu apenas para as fácies de arenitos grossos e conglomerados silexíticos pertencentes à parte superior da Formação Tatuí, não se utilizando tal denominação para os conglomerados associados às superfícies transgressivas que caracterizam o limite entre as duas unidades litoestratigráficas.

Agradecimentos Os autores agradecem à FAPESP pelo apoio financeiro (Processo n ${ }^{\circ}$ 98/02183-3) e pela bolsa de iniciação científica concedida a Angélica Álida Zacharias (Processo no 99/054787). Aos revisores da RBG pelas sugestões ao manuscrito.

\section{Referências}

Assine M.L., Zacharias A.A., Perinotto J.A.J. 1999. O trato deposicional Tatuí e a transgressão Taquaral no centro-leste do Estado de São Paulo. In: SBG, Simpósio de Geologia do Sudeste, 4, São Pedro, Resumos, p.53.

Barbosa O. \& Almeida F.F.M. 1949. A Série Tubarão na bacia do Rio Tietê, Estado de São Paulo. Boletim DNPM-DGM, 48, 16p.

Barbosa O. \& Gomes F.A. 1958. Pesquisa de petróleo na bacia do rio Corumbataí, Estado de São Paulo. Bol. Div. Geol. Mineral. DNPM, 71:1-40.

Câmara Filho L.M. 1997. Estratigrafia de Seqüências no Grupo Guatá na Faixa Sbaflorante do Sudeste paulista. Dissertação de Mestrado, Universidade Estadual Paulista, Instituto de Geociências e Ciências Exatas, Rio Claro, 221p.

Castro J.C. \& Câmara Filho L.M. 1995. Arcabouço estratigáfico do Grupo Guatá (Permiano Inferior) na margem aflorante paulista. In: SBG, Simp. Geol. Sudeste, 4, Águas de São Pedro, p.61.

Castro J.C., Michel U., Alves C.F.C., Grecchi R.C. 1993. O Grupo Guatá na margem nordeste da Bacia do Paraná: uma revisão. In: UNESP, Simp. Cronoestratigrafia da Bacia do Paraná, 1, Rio Claro, 55-56.

Fulfaro V.J., Stevaux J.C., Souza Filho E.E., Barcelos J.H. 1984. A Formação Tatuí (P) no Estado de São Paulo. In: SBG, 33 Congr. Bras. Geol., Rio de Janeiro, Anais, v.2, 711-724.

Gordon Jr. M. 1947. Classificação das formações gondwânicas do Paraná, Santa Catariana e Rio Grande do Sul. Boletim DNPM-DGM, 1:374385.
Mezzalira S. 1957. Ocorrências fossilíferas novas da série Passa Dois na região Limeira - Rio Claro - Piracicaba. Boletim SBG, 6:37-59.

Morales N., Perinotto J.A.J., D’Affonseca F.M. 1997. Evidências de tectônica distensiva sindeposicional à Formação Tatuí na região de Limeira - SP. In: SBG, Simp. Geol. Sudeste, 5, Itatiaia, Resumos, 60-61.

Perinotto J.A.J. 1992. Análise estratigráfica da formação Palermo $(P)$ na Bacia do Paraná, Brasil. Instituto de Geociências e Ciências Exatas, Universidade Estadual Paulista - Unesp, Tese de Doutorado, Rio Claro, 126 p.

Ragonha E.W. 1978. Chondrichthyes do Membro Taquaral (Formação Irati) no Estado de São Paulo. Instituto de Geociências, Universidade de São Paulo, São Paulo, Dissertação de Mestrado, 65p.

Riccomini C., Sant'Anna L.G., Coimbra A.M. 1997. Sílica microcristalina (Trípoli) em rochas sedimentares permianas do flanco leste da Bacia do Paraná, Estado de São Paulo, Brasil. Rev. Bras. Geoc., 27:395-402.

Soares P.C. 1972. O limite glacial - pós-glacial do Grupo Tubarão no Estado de São Paulo. Anais Acad. Bras. Ciências, 44:333-341.

Stevaux J.C., Souza Filho E.E., Fulfaro V.J. 1986. Trato deposicional da Formação Tatuí $(\mathrm{P})$ na área aflorante do NE da Bacia do Paraná, Estado de São Paulo. In: SBG, Congr. Bras. Geol., 34, Goiânia, Anais, v.1, 219-229.

Manuscrito A-1278

Recebido em 16 de novembro de 2001

Revisão dos autores em 10 de fevereiro de 2003 Revisão aceita em 15 de fevereiro de 2003 